\title{
DÜBLIN
}

Technological University Dublin

ARROW@TU Dublin

\section{A multi-discipline method to assess the human performance in manufacturing industry for safety and quality optimization}

\author{
Lorenzo Comberti \\ Politecnico di Torino \\ Micaela Demichela \\ Politecnico di Torino \\ Maria Chiara Leva \\ Technological University Dublin, mariachiara.leva@tudublin.ie
}

Follow this and additional works at: https://arrow.tudublin.ie/schfsehbk

Part of the Medicine and Health Sciences Commons

\section{Recommended Citation}

Comberti, Lorenzo \& Demichela, Micaela \& Leva, Maria. (2018). A multi-discipline method to assess the human performance in manufacturing industry for safety and quality optimization. 10.1201 / 9781351174664-48.

This Book Chapter is brought to you for free and open access by the School of Food Science and Environmental Health at ARROW@TU Dublin. It has been accepted for inclusion in Books/Book Chapters/ Proceedings by an authorized administrator of ARROW@TU Dublin. For more information, please contact arrow.admin@tudublin.ie, aisling.coyne@tudublin.ie,gerard.connolly@tudublin.ie.

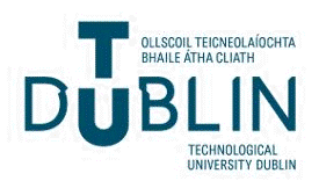




\title{
A multi-discipline method to assess the human performance in manufacturing industry for safety and quality optimization
}

\author{
Lorenzo Comberti \& Micaela Demichela \\ DISAT, Politecnico di Torino, Italy \\ Maria Chiara Leva \\ School of Food Science and Environmental Health, Dublin Institute of Technology (DIT), Dublin, Ireland
}

\begin{abstract}
Nowadays the majority of organizations operating in manufacturing field recognize the importance of including the Human Factor contribution in the industrial process optimization (Hong et al. 2007). Technical measures and work organization procedures have been optimized in order to reduce the defects and waste generation but the Human Performance prediction still represents for Managers a difficult task to deal with.The prediction of the human performances of all workers involved in a production system would help Managers in better allocating the human resources. In order to reach this objective, a model to quantify the human capability of managing a complex task in a working context characterized by a set of physical, organizational and cognitive factors was designed.This paper presents the preliminary results of a three years industry/academia partnership project to assess the human performance in manufacturing plant. A multi-discipline approach involving both technical and individual factors was adopted.
\end{abstract}

\section{INTRODUCTION}

In manufacturing sector, the process optimization plays an important role to improve the production efficiency and economical profits.

Production is influenced by several factors such as: technology, organization, energy and workers performance.

In many cases, process optimization has been primary focused on technical measures and work organization procedures.

The Human Factor, despite the level of automatization in manufacturing industry is considerably increased and the standardization of workingprocedures drives the working activity, still plays an important role on the efficiency of production system (Baines et al., 2005).

Human Factor has a strong influence on the occupational accident occurrence and defects generation.

Human Factor represents for Managers a difficult task to deal with even if most of organizations operating in manufacturing field recognize the importance of including the Human Factor (HF) contribution in the industrial process optimization (Hong 2007).

The Human Factor analysis has been approached differently in several areas.

Safety and Quality managers focused their attention to the deviation of human behavior from procedures. Miller (1987) analyzed a set of environmental, organizational and individual factors in relation to error-related outcomes. The ex-post events analysis approach has been used (Comberti et al., 2015) to identify causes of occupational accidents and defects with the aim of reducing their repetition.

Work Organization managers related the HF analysis to the ergonomic with the aim of calibrating and optimizing the task-time and reducing the operative risk task-related (Lin et al., 2001).

Many studies on Human Performance modeling suggest that the HF has to be approached as a complex system, where behavior, cognition, physiology and working condition deeply interact (Leva, 2016).

The knowledge of the relation between the human nature and the working condition of all workers involved in a production system would be crucial for the industrial Management.

Better allocating the human resources forward the different tasks will probably reduce the defects generation and the unsafe actions frequency.

In order to reach this objective it is necessary to model a system able to quantify and predict the human capability of managing a complex task in a context characterized by a set of physical, organizational and cognitive factors (Groth, 2012) in other words a model able to define and assess the Human Performance (HP). 
Relevant researchs in this topic suggested which variables can be used to define the HP.

Baine \& Benedettini (2007) suggested a multidisciplinary approach based on Sociology, Phycology and Engineering disciplines to be consistent on human nature representation. Eklund (1997) showed that Ergonomic has to be related to quality performances.

This paper presents the preliminary results of an industrial and academic project to develop a Human Performance assessment method for safety and quality optimization.

The aim of this work is to approach the HP modeling to facilitate the management of HF into the industrial improvement process.

The proposed model was developed on the basis of Straeter (2000) results.

It is based on the fundamental assumption that the HP can be represented as directly dependent from two macro-factors:

- Task Complexity (TC): that summarizes all factors contributing to the physical and mental requests to execute a given operative task, including work environmental factor.

- Human Capability (HC): that resumes the resources of workers under the real working condition. This factor represents both physical, mental and cognitive ability of the worker.

Section 2 of this paper presents the Conceptual Model of this project meanwhile section 3 shows the Operative Model deducted from the case study.

Section 3 gives an illustration of the project future development with a focus on the model validation. Conclusions will end the paper.

\section{HP PROJECT DESIGN}

This project has been managed in 4 steps as Figure 1 shows.

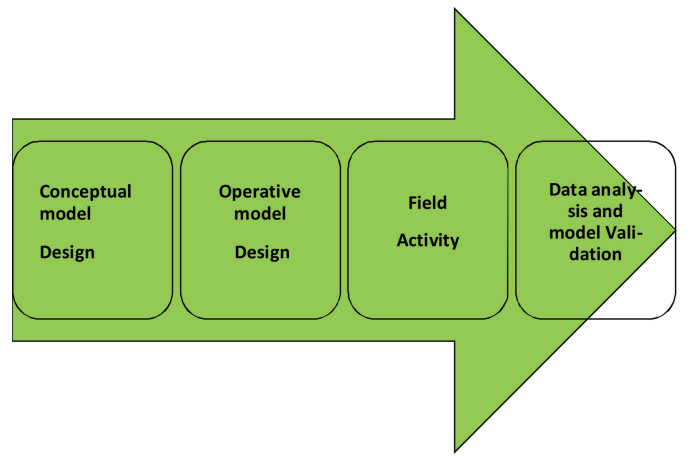

Figure 1. Project structure.
First step was focused on the "Conceptual Model" designing process.

Conceptual Model defines the variables and relations considered to the HP assessment.

Second step was characterized by the Operative model-design that represents the projection of Conceptual model into the industrial real life.

In other words each variables introduced into the Conceptual model have to be replaced by a measurable quantity into the Operative model.

Third step will be focused on HC and TC assessment with an intensive data field collection. This step will involves directly the workers of the plant with skill tests performed during the working activity.

In addition to this the descriptive parameters of TC will be collected with a deep analysis of working places. This step will be completed by a systematic interview of all workers involved. The interview will be structured on a set of questions related to individual motivation, risk-perception, working complexity perception. The information acquired with the survey will be used as a feedback for safety, work organization and quality improvements. On the basis of the results a validation or modification of the model will be done. This paper presents results related to the first and second steps of the project.

\subsection{Conceptual model}

The HP model represents the interaction between two macro factors: the Human Capability (HC) and the Task Complexity (TC).

Both factors can be analyzed with a wealth of methods for different purposes, such as data collection, task analysis (including cognitive task analysis), workload measurement, assessing situation awareness performance assessment (including team performance assessment), human error identification and interface evaluation methods (Stanton, 2004 and 2006).

In this work the proposed conceptual model of Human Performance is showed in Figure 2.

$\mathrm{TC}$, as mentioned in the previous section, represents the total demand of resources asked to perform correctly a given task under certain work environmental condition.

$\mathrm{TC}$ is the result of the contribution of two main factors: Mental Workload (MW) and Physical Workload (PW), both associated to a single operative task.

PW factor is easily relatable to the physical, motion and postural efforts required to complete a given task.

Bad ergonomics combined with time pressure (coping with pace) have been estimated to cause about $50 \%$ of all quality deviations (Lin, 2001). 


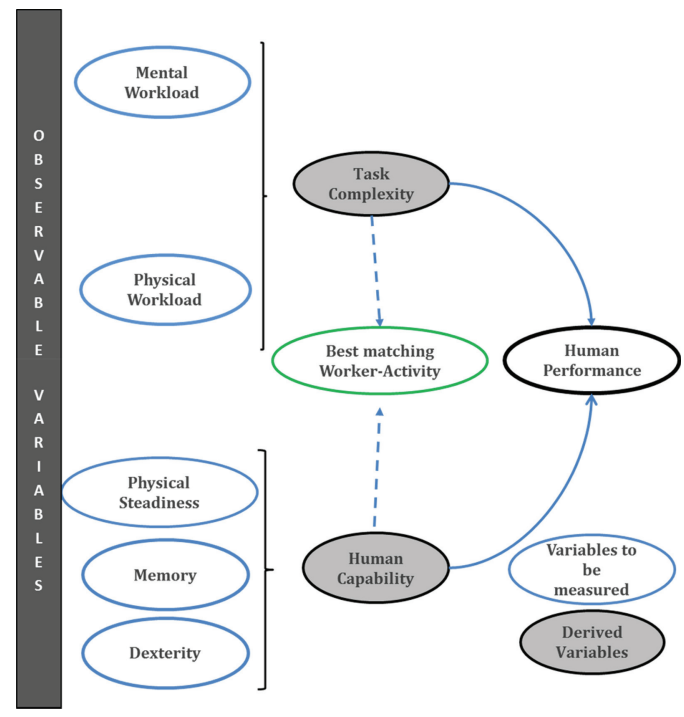

Figure 2. HP conceptual model.

Several studies demonstrates that high physical workload such as unkind postures can decrease the performance for discomfort (Erdinç, 2011).

A low variation, such as repetitive motions and static workload, was observed as additional cause for muscle fatigue (Punnett, 2000).

Other factors that may be included on PW modelling can be identified in the degree of rotation between high and low demanding tasks (Horton, 2012) and into the gender effects for the differences concerning discomfort and muscle fatigue in repetitive and static workload (Hunter, 2012).

In addition to the above mentioned factors, that are related to a specific operative task, other variables able to affect the PW are represented by environmental workload effects (Jung, 2001) which include: improper temperature, lighting, noise, vibration and exposure to chemical agents and physical agents as dust.

The physiological effects of these environmental factors, under industrial conditions, can contribute to an increase of the stress level and consequently to a loss of human performance (Grandejan, 1985).

MW was defined by Kahneman (1979) as "a factor directly related to the proportion of the mental capacity of an operator spends on task performance".

The MW assessment has been conducted in various research fields with both objectives and subjective measures such as: physiological activity under simple task normative condition (Kramer, 1991), cognitive performances, subjective analysis (Didomenico, 2008) and combined approach (Miyake, 2001).
All these studies have been performed in normative condition, with simple standardized tasks and under controlled environmental condition. This configuration is far away from industrial situation.

A relation between MW of assembly tasks and quality deviations was recently founded by Falck (2014). This work suggests that MW can be estimated trough the evaluation of the complexity of the task.

Operating in an industry plant it would be more suitable assessing the MW factor with a combination of subjective measurement and indirect task-related variable quantification, instead of approaching it with physiological measurement and cognitive normative test.

As a results of literature review and plant analysis a set of variables to TC definition was identified.

Figure 3 summarizes all variables selected to TC definition.

Human Capability (HC), as mentioned in the previous section, represents the total amount of resources that a worker is able to give for execute a given task under environmental working condition.

The $\mathrm{HC}$ factor is given by the contribution of several human skills that are all engaged in performing an operative task.

In particular the main Human skills that have been considered in relation to an assembly task are:

- Ability: skills like Precision, Manual Handling, Coordination are solicited continuously during a front line assembly work.

- Memory: remembering the sequence of operations and parts to complete correctly a given task can differ considerably.

- Physical: the ability of maintaining a constant performance during the shift and the ability of coping with pace.

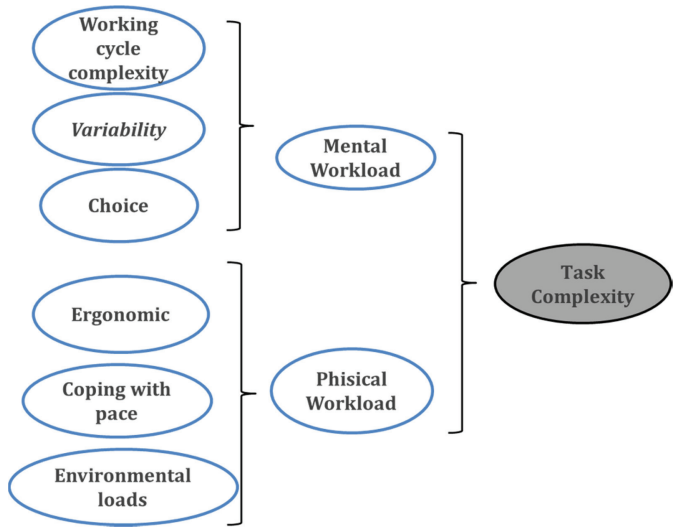

Figure 3. TC conceptual model. 


\subsection{Operative model}

The Conceptual model defined in the previous section represent also the trace for the Operative model definition.

Operative model contains for each factor taken into account into the Conceptual model a set of observable and measurable variables.

The variables were selected after a field analysis performed in the beginning stages of the project with a participatory approach that involved both academic and industry professionals operating in the various management areas involved: Safety, Work Analysis, Quality, Work Organization.

The observable variables selected will be measured both in numerical and qualitative scales.

In order to allow the confrontation between variables with different nature and scale, all the variables will be harmonized in a common numerical scale.

TC factor will be estimated trough the assessment of observable variables that are showed in Figure 4 (Mental Work Load) and in Figure 5 (Task Complexity).

In the proposed representation of Figures 4 and 5 some variables are not used directly into the HP model but are compared with the results of the workers interviews previously mentioned.

$\mathrm{HC}$ factors will be estimated trough a set of measures, showed in Figure 6.

These measures will be obtained as a results of skill tests performed by workers during the real working activity.

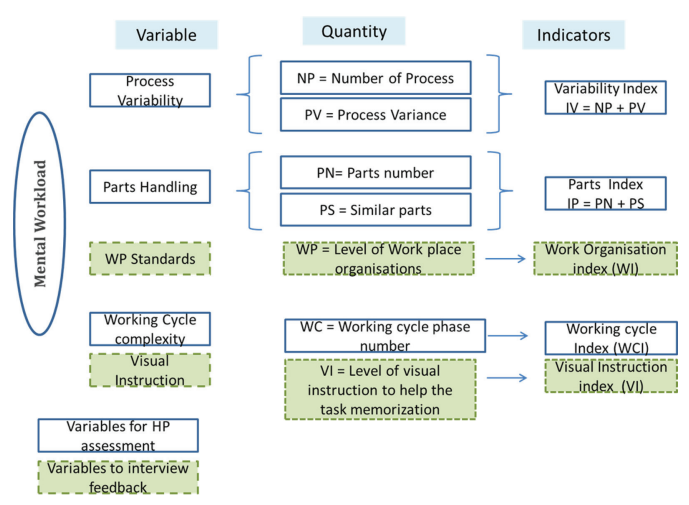

Figure 4. MW operative model.
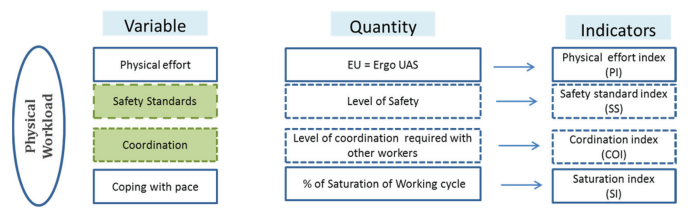

Figure 5. PW conceptual model.

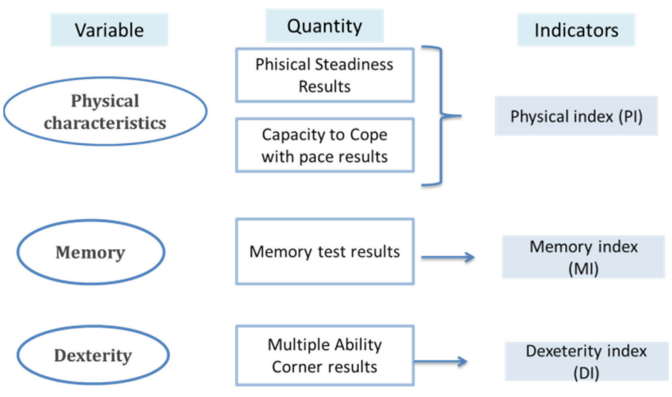

Figure 6. HC Operative model.

As an example the "Memory skill" will be tested recording the time spent by a worker to replicate a symbol sequence shortly showed.

Dexterity variable will be measured with 3 "ability tests" that simulate some typical operation asked into an assembly line.

The HC of each single workers will be assessed recording the time spent to complete all tests and recording the number of errors done.

In addition to these human skills, to model the Human Capability, it must be noticed that an important psycological aspects that can be described as "Motivation" can interact constructively or disprutively with this factor.

Motivation includes several psychological factors:

- Perception of task-risk;

- Perception of task complexity;

- Personal awarness;

- Job satisfactionldissatisfaction

It is conceptually easy to consider that a severe mismatch between Task complexity and Perceived Task Complexity can facilitate the human error or unsafe act generation.

Information acquired with the interview will be used to estimate the level of motivation and perception of each workers.

\section{PROJECT DEVELOPMENT AND MODEL VALIDATION}

Nowadays the project ended the second step. On the basis of the Operative model in the next 6 months a field data collection will be done. This activity will involves 150 workers operating in 4 assembly lines.

The total number of working places can be approximately estimated in 70 units. The application of this model will imply the calculation of 170 Human Capability profiles and 70 Task Complexity profiles. The HP calculation will be done according the scheme showed in Figure 7. 


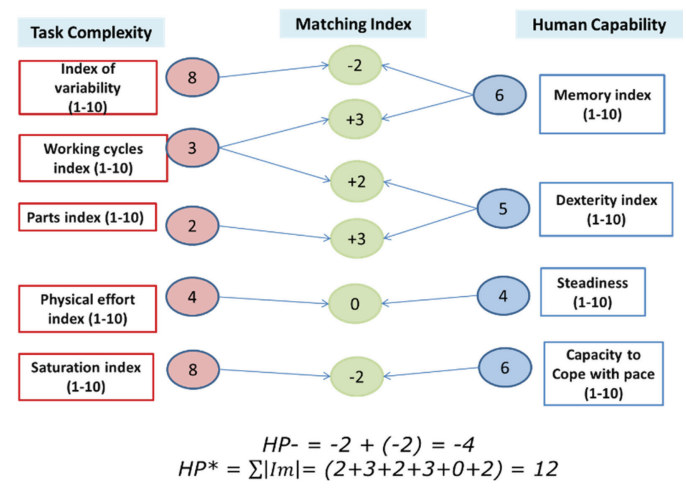

Figure 7. HP assessment.

Figure 7 summarize the generic scheme of calculation of HP between the TC of a working place characterized by 5 index (Variability, Working Cycles, Parts, Physical Efforts, Saturation) and the $\mathrm{HC}$ of a worker characterized by 4 index (Memory, Dexterity, Steadiness, Coping with pace).

This scheme of calculation is based on the operation "HC-index - TC-index" and leads to the definition of 6 matching indexs.

On the basis of the matching-index two Human Performance index are defined:

- HP-: represents the sum of all negatives matching index.

- HP*: represents the sum of all absolute values of matching index.

The assessment for each assembly line of HPand HP* will allows a quantitative calculation of the potential Human Performance related to the matching workers-working places.

Changing the distribution of the workers will leads to a different HP estimation.

Minimizing HP-and HP* will implies the optimization of the distribution of the workers forward the working places on the basis of each individual human capability and each task complexity.

To validate this model a collaborative processes involving Quality and Production Managers in mutual learning processes will be adopted as suggested by Action Research method (Greenwood, 2006).

A set of 25 working places with relevant problems of quality will be selected.

HP results will be used to identify the best matching workers-working places and on the basis of that a new configuration of the line will be done.

A period of 3 months will be used to monitor the results of the new configuration workers-tasks and quality indicators will be collected.
The comparison of quality data ante and post configuration will allows the evaluation of the impact of the method.

This operation would leads to a reduction of human error related to a wrong matching workerworking place.

The HP assessment would be used as a sort of objective guideline to optimize the workers distribution into assembly lines.

The number of workers involved (more than 150 ) and working places analyzes will allows a statistical validation of the model.

\section{CONCLUSION}

Conclusively, the strengths of the proposed empirical approach with respect to the Human Performance assessment can be summarized as it follows:

- a model to HP definition as the ultimate product of the balance between the TC (driven by all the factors from the environment) and the operator characteristics (HC) was developed.

- The empirical based analysis will enhance the knowledge of the specific process operations at Managerial level, possibly highlighting latent drivers of Human Performance.

- This model was developed and will be tested in real operative condition and with a large number of workers directly involved. That represents a rare case of cooperation between academia and manufacturing. Results of the model application will be directly applied by industrial management with a measurable impact in term of process optimization.

\section{REFERENCES}

Baine T.S., Benedettini, O., 2007 Modelling human performance within manufacturing systems design: from a theoretical towards a practical framework, Journal of Simulation, Volume 1, pp 121-1306. National Center for Biotechnology Information.

Baines, T.S., Asch, R., Hadfield, L., Mason, J.P., Fletcher, S., Kay, J.M., 2005, Towards a theoretical framework for human performance modelling within manufacturing systems design. Simulation Modelling Practice and Theory, Vol. 13(6), pp. 451-524.

Comberti L., Baldissone, G., Bosca, S., Demichela, M., Murè, S., Petruni, A., Djapan, M., Cencetti, S. Comparison of two methodologies for occupational accidents pre-cursors data collection, 2015, European Safety and Reliability Conference, ESREL 2015, At Zurich, Switzerland.

DiDomenico, A., Nussbaum, M.A., 2008. "Interactive effects of physical and mental workload on subjective workload assessment. International Journal of Industrial Ergonomics 28, 977-983. 
Eklund, J. 1997. "Ergonomics, Quality and Continuous Improvement conceptual and Empirical Relationships in an Industrial Context." Ergonomics 40: 982-1001.

Erdinç, O., Yeow. P.H.P. 2011. "Proving External Validity of Ergonomics and Quality Relationship through Review of Real-World Case Studies." International Journal of Production Research 49: 949-962.

Falck, A.C., R. Örtengren, and M. Rosenqvist. 2014. "Assembly Failures and Action Cost in Relation to Complexity Level and Assembly Ergonomics in Manual Assembly (Part 2)." International Journal of Industrial Ergonomics 44: 455-459.

Grandejan, E., 1985. Fitting the Task to the Man-An Ergonomic Approach. Taylor and Francis, London.

Greenwood, D.J., \& Levin, M. (2006). Introduction to action research: Social research for social change. SAGE publications.

Groth K.M., Mosleh, A., 2012. A data-informed PIF hierarchy for model - based Human Reliability Analysis, Reliability Engineering and System Safety 108, pp. 154-174.

Hong K., Nagaraja R., P. Iovenitti, M. Dunn, A sociotechnical Approach to Achieve Zero Defect Manufacturing of Complex Manual Assembly, 2007, Human Factor and Ergonomics in Manufacturing, Vol. 17 (2), pp. 137-148.

Horton, L.M., Nussbaum M.A., Agnew M.J., 2012. "Effects of Rotation Frequency and Task Order on Localised Muscle Fatigue and Performance during Repetitive Static Shoulder Exertions." Ergonomics 55: 1205-1217.

Hunter, S.K. 2014. "Sex Differences in Human Fatigability: Mechanisms and Insight to Physiological Responses." Acta Physiologica 210: 768-789.

Jung, H.S.,Jung HS. 2001.”Establishment of overall workload assessment technique for various tasks and workplaces". International Journal of Industrial Ergonomics 28: 341-353.

Kahneman, D., Tversky, A. 1979. Prospect theory: An analysis of decision under risk. Econometrica, 47, pp. 263-291.

Kramer, A.F., 1991. Physiological metrics of mental workload: a review of recent progress. In: Damos, D.L. Ed., Multiple task performance. Taylor \& Francis, London, pp. 279-328.

Leva, M.C., Ciarrapica Alunni, C., Demichela M., Allemandi, G., Adressing human performance in automotive industry: identifying main drivers of human reliability. Irish Ergonomics Review 2016 Proceedings of the Irish Ergonomics society Annual Conference.

Lin, L., C. g. Drury, and S.-W. Kim. 2001. "Ergonomics and Quality in Paced Assembly Lines." Human Factors and Ergonomics in Manufacturing 11: 377-382.

Miller, D.P., Swain, A.D., 1987, Human error and human reliability. Handbook Human Factor, Wiley-Interscience, New York.

Miyake, S., 2001. Multivariate workload evaluation combining physiological and subjective measures. International Journal of Psychophysiology 40, 233-238.

Punnett, L., L.J. Fine, W.M. Keyserling, g. D. Herrin, and D.B. Chaffin. 2000. "Shoulder Disorders and Postural Stress in Automobile Assembly Work." Scandinavian Journal of Work, Environment \& Health 26: 283-291.

Stanton, N.A., (2004). Hierarchical Task Analysis: Developments, Applications and Extensions. Applied Ergonomics, 37, 55-79.

Stanton, N.A., et al., 2005. Human factors methods: A practical guide for engineering and design. Aldershot, UK: Ashgate.

Straeter O. 2000. Evaluation of Human Reliability on the basis of Operational Experience. GRS-170 Cologne (Germany) GRS. 